\title{
The Initial Equilibrium Steps in the Interactions of Bovine Plasma Albumin and Zinc(II) Ions. A Potentiostatic Study
}

\author{
RAG NAR ÖSTERBERG \\ Department of Medical Biochemistry, University of Göteborg, \\ S-400 33 Göteborg 33, Sweden
}

\begin{abstract}
The equilibria between bovine plasma albumin (L) and zinc(II) ions have been investigated at $25^{\circ}$ by potentiostatic emf titrations using glass and zinc amalgam electrodes. The ionic medium was $0.5 \mathrm{M} \mathrm{NaClO}$, and the $\mathrm{pH} \mathrm{6.78.} \mathrm{The} \mathrm{total} \mathrm{concentrations} \mathrm{of} \mathrm{albumin}$ and zinc ions varied through the ranges $0.02-0.5 \mathrm{mM}$ and $0.1-1.7$ $\mathrm{mM}$, respectively. For each titration the potentiostatic technique involved generating both $\mathrm{Zn}^{2+}$ and $\mathrm{H}^{+}$ions to constant emf values by using constant current electrolysis. The amount of electricity used was measured by a coulometer.

When the total zinc concentration is plotted against the albumin concentration, the potentiostatic data directly indicate that monomeric albumin complexes predominate at low zinc ion concentrations and that some zinc-albumin polymers exist at high concentrations. The data were further examined using a graphical approach and a computer. The results were found to be consistent with the formation of the monomers $\mathrm{ZnL}$, and $\mathrm{Zn}_{\mathbf{2}} \mathrm{L}$, and the series of polymers $\mathrm{ZnL}\left(\mathbf{Z n}_{5} \mathbf{L}\right)_{n}$ where $n=1,3$, and 5 . The magnitudes of the constants obtained for these polymers indicate that they apparently form via zinc ions. It is suggested that this type of polymerization may be of importance in plasma fractionation procedures in which albumin is precipitated by the presence of zinc ions.
\end{abstract}

$\mathrm{T}$ he zinc ion appears to be one of the most important metal ions in physiological systems: Zinc ions are present in the active sites of several enzymes, and it is generally held that they are directly involved in the enzymic processes. In blood plasma there are about $0.05 \mathrm{mM}$ zinc ions which are mainly transported as albumin complexes. ${ }^{1}$ The affinities of albumin, and some other proteins, for zinc ions have been exploited in plasma fractionation procedures. ${ }^{2}$ The proteins can be selectively precipitated at relatively low zinc concentrations. However, little is known concerning the mechanism causing their reduced solubilities. 
The main object of this work has been to investigate the initial complexes formed between zinc ions and plasma albumin molecules. On this subject there are obviously disagreements about the number of zine ions that are bound, although most investigators agree that as far as albumin is concerned, only monomers are involved (Table 1).

Table 1. Survey of investigations on the primary interactions of zinc(II) ions with plasma albumin.

\begin{tabular}{|c|c|c|c|c|c|c|c|}
\hline \multirow{2}{*}{$\begin{array}{l}\text { Reference } \\
\text { Tanford so }\end{array}$} & \multirow{2}{*}{$\frac{\underset{\mathrm{mM}}{A}}{0.18}$} & \multirow{2}{*}{$\begin{array}{c}\begin{array}{c}B \\
\mathrm{mM}\end{array} \\
0.4\end{array}$} & \multicolumn{2}{|c|}{$\begin{array}{c}\mathrm{pH} \text { and } \\
\text { temperature }\end{array}$} & \multirow[t]{2}{*}{ Medium } & \multirow{2}{*}{$\begin{array}{c}\begin{array}{c}\text { Primary } \\
\text { binding } \\
\text { sites }^{a}\end{array} \\
17\end{array}$} & \multirow{2}{*}{$\frac{\log K}{2.9}$} \\
\hline & & & $5-9$ & $\left(25^{\circ}\right)$ & & & \\
\hline Saroff and Mark ${ }^{31}$ & $0.1-0.6$ & $0.2-0.4$ & 6.1 & $\left(26^{\circ}\right)$ & $0.1 \mathrm{M} \mathrm{NaAc}$ & 8 & 3.1 \\
\hline Kacona ${ }^{32}$ & $0.01-0.4$ & 1.0 & 8.5 & $\left(25^{\circ}\right)$ & $0.1 \mathrm{M} \mathrm{NaCl}$ & 50 & 3 \\
\hline Rao and Lal ${ }^{10}$ & 0.15 & $0.1-2.0$ & 6.50 & $\left(30^{\circ}\right)$ & $0.2 \mathrm{M} \mathrm{NaAc}$ & 2 & 3.9 \\
\hline Present work & $0.02-0.5$ & $0.1-1.7$ & 6.78 & $\left(25^{\circ}\right)$ & $0.5 \mathrm{M} \mathrm{NaClO}$, & 1 & $9.6^{b}$ \\
\hline Gurd and Goodman $8 \mathrm{c}$ & 0.35 & $1-10$ & $5.5-7.5$ & $\left(0^{\circ}\right)$ & $0.15 \mathrm{M} \mathrm{NaNO}$ & 16 & 2.8 \\
\hline Waldmann-Meyer $38 c$ & - & - & 6.07 & $\left(25^{\circ}\right)$ & $0.15 \mathrm{M} \mathrm{NaAc}$ & 17 & 2.8 \\
\hline Perkins $20 \mathrm{C}$ & 0.1 & - & $4.5-8.5$ & $(-)$ & $0.15 \mathrm{M} \mathrm{NaCl}$ & $1-5$ & - \\
\hline
\end{tabular}

all species of type $\mathrm{Zn}_{p} \mathrm{~L}$.

${ }^{6}$ Interaction with a thiol group is assumed. An imidazole or a carboxylate group gives 6.5 and 6.4, respectively.

$c$ Human albumin, assumed mol.wt. 69000.

In the present study the data have been treated by methods which are markedly different from those used previously. Thus, an analysis of $p$ and $r$ (the number of $\mathrm{Zn}^{2+}$ and albumin molecules $(\mathrm{L})$ bound to the main species) was carried out without introducing any assumptions regarding the compositions of the complexes except that they conform to the general formula, ${ }^{*}$ $\mathrm{Zn}_{p} \mathrm{~L}_{r}$. It is necessary in this analysis that some of the free concentrations can be considered constant, and so the data were recorded potentiostatically. This was carried out by coulometric emf titrations, in which the total concentration of albumin and zinc ions were varied and the free concentrations of $\mathrm{Zn}^{2+}$ and $\mathrm{H}^{+}$were held constant. Due to the fact that the $\mathrm{pH}$ was also held constant throughout the measurements, the treatment of the experimental data did not require considerations concerning the number of protons bound. Thus, the problem of finding the triplets $(p, q, r)$ for the predominating species of general formula, $\mathrm{Zn}_{p} \mathrm{H}_{q} \mathrm{~A}_{r}(2 p+q-r y)+$, was reduced to one of finding just the pairs $(p, r)$.

\section{Notations}

$A$, total concentration of plasma albumin as defined by eqn. 4; $a$, molar concentration of free albumin; $B$, total concentration of $\mathrm{Zn}^{2+}$ as defined by eqn. $5 ; b$, molar concentration of free $\mathrm{Zn}^{2+} ; h$, molar concentration of free

* For simplicity, the more general formula for a zinc(II)-albumin complex, $\mathrm{Zn}_{p} \mathbf{H}_{q} \mathbf{A}_{r}(2 p+q \rightarrow y)+$, is reduced to $\mathrm{Zn}_{p} \mathrm{~L}_{r}$, when the $\mathrm{pH}$ is constant. $\mathrm{L}$ stands for albumin including all different protonated forms that may enter the complexes ( $c f$. eqns. 4-6). 
$\mathrm{H}^{+} ; F_{p r}$, "formation" constant at constant $h$ as defined by eqn. 6 ; when $a$ is normalized, $a$ is replaced by $\mathrm{aF}_{01}{ }^{-1}$ (eqn. 9) and the constant relating to each species, $\mathrm{Zn}_{p} \mathrm{~L}_{r}$, becomes $F_{p r} F_{01} \rightarrow p, r$, number of $\mathrm{Zn}^{2+}$ and albumin molecules (L) bound in $\mathrm{Zn}_{p} \mathrm{~L}_{r} ; \bar{p}, \bar{r}$, average number of $p, r$;

$$
\begin{aligned}
& Z_{B}=(B-b) / A=\left(\sum_{p} \sum_{q} p\left[\mathrm{Zn}_{p} \mathrm{H}_{q} \mathrm{~A}\right]\right) /\left(\sum_{q}\left[\mathrm{H}_{q} \mathrm{~A}\right]+\sum_{p} \sum_{q}\left[\mathrm{Zn}_{p} \mathrm{H}_{q} \mathrm{~A}\right]\right)= \\
& =\left(\sum_{p} p b^{p} F_{p 1} F_{01}^{-1}\right) /\left(1+\sum_{p} b^{p} F_{p 1} F_{01}^{-1}\right) \quad \text { at constant } h \text { and for } r=1 \mid
\end{aligned}
$$

(cf. eqns. $3-6$ and eqn. 9).

\section{EXPERIMENTAL}

Materials. The crystalline bovine plasma albumin (BPA) used in these studies was an Armour product (Lot No. D 71209). A solution of about 1.5 mM BPA in 0.5 M NaClO was freshly prepared for every second titration. A molecular weight of 66700 was assumed..$^{3}$ After filtering the solution (Millipore $0.45 \mathrm{~m} \mu$ ) the $\mathrm{pH}$ was increased at $4^{\circ}$ by generating $\mathrm{OH}^{-}$ions at a platinum gauze immersed in the solution. ${ }^{4}$ Thereby, the albumin solution is maintained in a reducing environment so that the tendency for half-cystine residues to form disulfide bonds will be minimized. This method avoids a high localized $\mathrm{OH}^{-}$concentration as well as the impurities of commercial sodium hydroxide. ${ }^{5}$ The solution so obtained was dialysed against several portions of $0.5 \mathrm{M} \mathrm{NaClO}_{4}$ of the same $\mathrm{pH}\left(2\right.$ days at $\left.4^{\circ}\right)$. It was then tested for metal ion impurities and gave a negative result. The albumin in the final solution moved as a single component in sedimentation velocity experiments (Spinco Model E ultracentrifuge at $22^{\circ}$ and $52600 \mathrm{rpm}$ ). Further one very faint component was detected by polyacrylamide electrophoresis in $0.1 \mathrm{M} \mathrm{NaClO}{ }_{4}$. The distance moved was what might be expected for albumin dimers. It was estimated that this minor component constituted $<5 \%$ of the albumin. The concentration of albumin was usually determined by measuring the optical density at $279 \mathrm{~m} \mu$ using $E(1 \%$, $1 \mathrm{~cm}$ ) $=6.67$ (Ref. 6). This procedure was checked by heating the protein to constant weight at $110^{\circ}$ and by a micro-Kjeldahl method.

Zinc perchlorate was prepared by dissolving $\mathrm{ZnO}$ (Merck, p.a.) in $\mathrm{HClO}_{4}$ and crystallizing the $\mathrm{Zn}\left(\mathrm{ClO}_{4}\right)_{2}$ thrice from water. It was also prepared by another route ${ }^{7}$ using $99.999 \%$ pure zine (Fluka AG) and oxygen. These two preparations did not show any measurable differences when the constant, $E_{0 Z n}$, was determined by the procedure to be described later (cf. Table 2). The zinc ion concentration of the stock solutions were determined by titrating with EDTA using diphenylthiocarbazone as an indicator. The solutions containing albumin were analysed for zinc ions according to the method described by Gurd and Goodman. ${ }^{8}$ The mercury (Grave, p.a.) was first subjected to electrolysis in dilute $\mathrm{HNO}_{3}$ so that small metal impurities could be eliminated. Then it was distilled thrice in the presence of air at $200^{\circ}$. Sodium perchlorate was taken from the batch described in a previous paper. ${ }^{9}$ Triply distilled water, freshly prepared in a quartz apparatus, was used throughout.

Method. The equilibria were measured by emf titrations in which $A$, the total concentration of albumin, and $B$, the total concentration of zinc ions, were varied. In each titration the free concentrations of both $\mathrm{Zn}^{2+}(b)$ and $\mathrm{H}^{+}(h)$ were held constant. These ions were generated by constant current electrolysis. The equilibrium concentrations were recorded after each generation by using zinc amalgam and glass electrodes.

The electrolysis circuit was

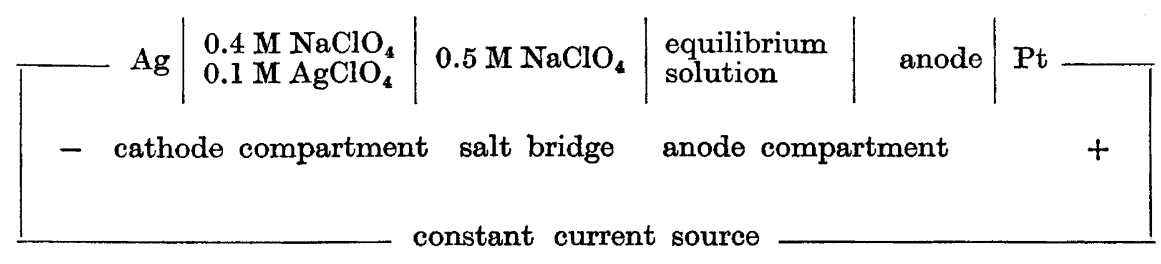

Acta Chem. Scand. 25 (1971) No. 10 
Table 2. The last two parts of a series of experiments. In the first two parts the constant $\mathrm{H}_{\mathrm{OG}}=161.0 \mathrm{mV}$, was determined and the measuring amalgam $(0.016 \mathrm{~mol} \% \mathrm{Zn})$ was propared. The generating amalgam $(0.016 \mathrm{~mol} \% \mathrm{Zn})$ has been added before the start of the third part. Data of the solution: volume $=24.10 \mathrm{ml} ;\left[\mathrm{Na}^{+}\right]=496.9 \mathrm{mM} ; B=1.673 \mathrm{mM}$, $\left[\mathrm{ClO}_{4}^{-}\right]=500 \mathrm{mM}$.

\begin{tabular}{|c|c|c|c|c|c|}
\hline$\underset{\left(\mu F^{\prime} / \mathrm{ml}\right)}{\mu_{2 \mathrm{n}^{a}}{ }^{a}}$ & $\underset{(\mu F / \mathbf{m l})}{\mu_{\mathbf{H}}{ }^{a}}$ & $\begin{array}{c}\text { BPA } \\
1.455 \mathrm{mM} \\
\text { (ml) }\end{array}$ & $\begin{array}{l}E_{\mathrm{Zn}} \\
(\mathrm{mV})\end{array}$ & $\begin{array}{l}\boldsymbol{E}_{\mathrm{G}} \\
(\mathrm{mV})\end{array}$ & $\begin{array}{l}E_{\mathrm{uz}} \\
(\mathrm{mV})\end{array}$ \\
\hline $\begin{array}{l}-1.422 \\
-1.680 \\
-1.938 \\
-2.196 \\
-2.456 \\
-2.716 \\
-2.972 \\
-3.018\end{array}$ & & $E_{0 \mathrm{Zn}_{\mathbf{n}}}=14$ & $\begin{array}{l}1463.6 \\
1465.7 \\
1467.7 \\
1471.2 \\
1475.1 \\
1480.9 \\
1493.2 \\
1495.2 \\
\mathrm{i} V\end{array}$ & $\begin{array}{l}416.1 \\
428 \\
452\end{array}$ & $\begin{array}{l}1461.5 \\
1461.5 \\
1461.4 \\
1461.5 \\
1461.5 \\
1460.9 \\
1461.6 \\
1462\end{array}$ \\
\hline-2.934 & 0.025 & 0.508 & $\begin{array}{l}1513.7 \\
1511.2 \\
1509.6\end{array}$ & $\begin{array}{l}390.3 \\
389.7 \\
384.5\end{array}$ & \\
\hline $\begin{array}{l}-2.818 \\
-2.776 \\
-2.747\end{array}$ & 0.045 & 1.002 & $\begin{array}{l}1516.3 \\
1513.8 \\
1510.8 \\
1509.6\end{array}$ & \begin{tabular}{|l|}
$\mathbf{3 8 9 . 6}$ \\
$\mathbf{3 8 8 . 8}$ \\
$\mathbf{3 8 7 . 4}$ \\
$\mathbf{3 8 4 . 7}$
\end{tabular} & \\
\hline $\begin{array}{r}-2.627 \\
-2.587 \\
-2.577 \\
-\mathbf{2 . 5 7 3}\end{array}$ & $\begin{array}{l}0.056 \\
0.062\end{array}$ & 1.512 & $\begin{array}{l}1516.0 \\
1511.7 \\
1510.7 \\
1509.8 \\
1509.7\end{array}$ & \begin{tabular}{|l|}
388.9 \\
\\
386.6 \\
385.3 \\
384.9 \\
\end{tabular} & \\
\hline $\begin{array}{l}-2.463 \\
-2.413\end{array}$ & $\begin{array}{l}0.0728 \\
0.0788 \\
0.0847\end{array}$ & 2.015 & $\begin{array}{l}1515.0 \\
1510.7 \\
1509.9 \\
1509.7 \\
1509.6\end{array}$ & $\begin{array}{l}388.2 \\
386.6 \\
385.6 \\
385.1 \\
384.7\end{array}$ & \\
\hline-2.259 & 0.1008 & 2.516 & $\begin{array}{l}1510.2 \\
1509.7\end{array}$ & $\begin{array}{l}386.1 \\
384.8\end{array}$ & \\
\hline $\begin{array}{l}-2.120_{5} \\
-2.110_{8} \\
-2.106\end{array}$ & 0.1162 & 3.016 & $\begin{array}{l}1510.7 \\
1510.0 \\
1509.7 \\
\end{array}$ & $\begin{array}{l}385.2_{5} \\
384.9_{5} \\
384.8\end{array}$ & \\
\hline $\begin{array}{l}-1.8633 \\
-1.830 \\
-1.824 \\
-1.821 \\
\end{array}$ & $\begin{array}{l}0.1398 \\
\\
0.1454 \\
0.1510 \\
\end{array}$ & 4.016 & $\begin{array}{l}1511.0 \\
1510.4 \\
1510.1 \\
1509.7 \\
\end{array}$ & $\begin{array}{l}\mathbf{3 8 6 . 3} \\
\mathbf{3 8 5 . 6} \\
\mathbf{3 8 5 . 3} \\
\mathbf{3 8 4 . 7} \\
\end{array}$ & \\
\hline $\begin{array}{l}-1.581 \\
-1.540 \\
-1.531 \\
-1.522 \\
\end{array}$ & 0.1780 & 5.016 & $\begin{array}{l}1511.0 \\
1510.6 \\
1510.1 \\
1509.7 \\
\end{array}$ & $\begin{array}{l}386.0 \\
385.3 \\
385.1 \\
384.9 \\
\end{array}$ & \\
\hline $\begin{array}{l}-1.0327 \\
-1.0126^{6}\end{array}$ & $\begin{array}{l}0.2169 \\
0.2219 \\
0.2269\end{array}$ & $7.017^{b}$ & $\begin{array}{l}1510.2 \\
1509.8 \\
1509.7\end{array}$ & $\begin{array}{l}385.3 \\
385.0 \\
384.7\end{array}$ & \\
\hline
\end{tabular}

${ }^{a}$ Generated $\mathrm{Zn}^{2+}$ and $\mathrm{H}^{+} .{ }^{b}$ Corresponds to $A=0.328 \mathrm{mM}, B=0.712 \mathrm{mM}$; analysis gave 0.326 and $0.72 \mathrm{mM}$. 
The anode material was either zinc amalgam or a platinum gauze, the former being situated in a pocket of the titration vessel and the latter near to the surface of the solution. It is assumed that the volume and temperature changes occurring during electrolysis are negligible. ${ }^{4}$ The current was passed at a rather slow rate, $0.3 \mu F / \mathrm{min}$. In order to avoid a local excess of the ions formed in the vicinity of the anode, the amount of electricity required for each point was added by passing the current in steps. Magnetic stirring on the amalgam surface and bubbling argon through the solution were used as means of obtaining efficient mixing. However, in order to eliminate small amounts of oxygen molecules formed on the platinum gauze when $\mathrm{H}^{+}$was generated $\left(4 \mathrm{H}^{+} / \mathrm{O}_{2}\right)$, the magnetic stirring was stopped and the stream of argon increased.

The emf's were measured for cells of the following type

$$
\mathrm{ME} / \text { equilibrium solution/0.5 } \mathrm{M} \mathrm{NaClO} / \mathrm{SE}
$$

where ME is a zinc amalgam or a glass electrode. SE is the reference $\mathrm{Ag}, \mathrm{AgCl}$ half cell (containing $\mathrm{NaClO}_{4}$ ) as described by Biedermann. ${ }^{10}$ The equilibrium solution, the reference half cell and the salt bridge were all $0.5 \mathrm{M}$ in $\mathrm{ClO}_{4}^{-}$. On this basis it is assumed that the variations of the activity factors are effectively reduced so that all the species in solution may be considered in terms of concentrations. ${ }^{11}$ The emf's for the zinc amalgam $\left(E_{\mathrm{Zn}}\right)$, and glass electrode $\left(E_{\mathrm{G}}\right)$ cells may thus be represented by the equations

$$
\begin{aligned}
& E_{\mathrm{Zn}}=E_{0 \mathrm{Zn}}-29.577 \log b+E_{\mathrm{j}} \\
& E_{\mathrm{G}}=E_{0 \mathrm{G}}-59.155 \log h+E \mathrm{j}
\end{aligned}
$$

where $E_{0 \mathrm{Zn}}$ and $E_{0 \mathrm{G}}$ are constants. The liquid junction potential, $E_{\mathrm{j}}$, arising at the junction between the equilibrium solution and $0.5 \mathrm{M} \mathrm{NaClO}_{4}$ was approximated by $E_{\mathrm{j}},=+150 \mathrm{~h} \mathrm{mV}$. It is not far from $E_{\mathrm{j}},=+136 \mathrm{~h} \mathrm{mV}$, obtained by the hydrogen half cell.?

Emf titrations. Each series of experiments may be divided into four parts: (1) determination of the constant, $E_{0 \mathrm{G}}$, (2) preparation of the measuring amalgam, (3) determination of the constant, $E_{0 Z n}$, and ultimate preparation of the generating amalgam, and (4) recording of the data $(B, A, b, h)$.

The constant, $E_{0 G}$, is determined in the absence of both zinc and albumin from a coulometric emf titration with $\mathrm{OH}^{-}$, using the initial solution of about $5 \mathrm{mM} \mathrm{H}^{+}$and the glass electrode cell ( $c f$. Ref. 12). Then in the next step, a zinc(II) solution is added and the measuring zinc amalgam is prepared in a pocket of the titration vessel that has been previously charged with mercury. Both for generating $\mathrm{OH}^{-}$ions and for preparing the zinc amalgam, the electrolysis circuit $(I)$ is reversed and uses a platinum gauze or mercury (zinc amalgam) as a cathode.

When the zinc(II) concentration in the solution has decreased to a set value, another zinc amalgam (the generating amalgam) is introduced into a second pocket of the titration vessel. In order to keep oxygen contamination to a minimum this amalgam is prepared, immediately before transfer, in a glass vessel connected to the titration vessel by ground glass joints. By using this latter amalgam as the cathode, the zinc(II) concentration is further reduced by stepwise electrolysis until a concentration of 0.05 to $0.1 \mathrm{mM}$ is attained. From the emf's recorded after each step, using the first amalgam as an electrode, the constant for the amalgam cell, $E_{0 \mathrm{Zn}}$, is calculated (Table 2). The final concentration of zinc in this second zinc amalgam usually became 0.02 to $0.04 \mathrm{~mol} \%$.

Finally, an albumin solution having $-\log h>-\log h_{0}$, is successively added and $h$ and $b$ are held constant at $h_{0}$ and $b_{0}$. This is arranged by generating $\mathrm{Zn}^{2+}$ and $\mathrm{H}^{+}$in steps (circuit I) so that $h$ and $b$ become equal to $h_{0}$ and $b_{0}$. The values of $h$ and $b$ are checked after each step by measuring the emf's of the zinc amalgam and glass electrode cells (II). An example of the procedure is shown in Table 2. It should be noted that there was a decrease in the $\mathrm{pH}$ when the zinc ions were generated into the albumin solutions containing $\mathrm{Zn}^{2+}$.

We also attempted to investigate the equilibria by varying $B$ as a function of $b$ for constant $h$ and constant $A$. The first three parts of this series of experiments were carried out as described above. Then samples of an albumin solution were added to the reaction vessel until the concentrations $A_{0}$ and $h_{0}$ were obtained. Then finally the zinc ion concentration was increased successively by using a titrant containing $0.05 \mathrm{M} \mathrm{Zn}\left(\mathrm{ClO}_{4}\right)_{2}$ and $0.4 \mathrm{M} \mathrm{NaClO}_{4}$. After each addition of $\mathrm{Zn}^{2+}$, the value of $h$ was adjusted to the constant value, $h_{0}$, using two albumin solutions having $A=A_{0}$ and $h$-values partly above and

Acta Chem. Scand. 25 (1971) No. 10 
partly below $h_{0}$. The ultimate adjustment of $h$ was usually made by generating $\mathbf{H}^{+}$by the circuit (I). The values of $h$ and $b$ were obtained from eqns. 1 and 2 using emf's recorded by cells of the type II.

The $A$ range was $0.02-0.5 \mathrm{mM}$ and $B$ was $0.1-1.7 \mathrm{mM}$. In an attempt to extend the $B$ range by using the titration procedure of the second type described we obtained a precipitate of albumin at $B \sim 8 \mathrm{mM}$ and $A=0.35 \mathrm{mM}$. The precipitate could be dissolved by diluting the solution with $0.5 \mathrm{M} \mathrm{NaClO}_{4}$. The emf's usually attained constant values within 20 min when the concentration of free $\mathrm{Zn}^{2+}$ was higher than $10 \mu \mathrm{M}$; however, at low values of $B$ the readings were constant only after 1 to $2 \mathrm{~h}$. The potentials then remained constant within $0.1-0.2 \mathrm{mV}$ for more than $12 \mathrm{~h}$. At the end of each titration, the solution was frozen and kept at $-20^{\circ}$ until it was analysed for zinc ions and albumin.

Apparatus. All the experiments were made in a closed apparatus, and the titration vessel was connected by ground glass joints to inlets for electrodes and argon gas (inlet and outlet). This apparatus was immersed in a paraffin oil thermostat kept at $25.00 \pm 0.01^{\circ}$ in a room thermostated at $25.0 \pm 0.1^{\circ}$. Oxygen was carefully excluded by bubbling argon through the solution. The argon was freed from $\mathrm{O}_{2}$ by hot activated copper and then passed through solutions of $10 \% \mathrm{NaOH}, 10 \% \mathrm{H}_{2} \mathrm{SO}_{4}, 0.5 \mathrm{M} \mathrm{NaClO}$, and finally $0.5 \mathrm{M} \mathrm{NaClO}$, within the oil bath. Attempts were made to reduce the oxygen content of the titrants by pretreating them with this purified, bubbling argon.

The glass electrodes, Beckman No. 40498, were calibrated against a hydrogen electrode. 'The emf's were measured by digital voltmeters (Digital Measurements, type DM 2022S). They were calibrated by a Leeds and Northrup compensator type K2 using a Weston standard cell. A similar cell was also connected across the zinc amalgam electrode in order to reduce the magnitude of the emf's measured. The constant current source (cf. I) was manufactured by Electronic Measurements (No. C 612). It was calibrated before every second or every third measurement. The variations in the currents between two consecutive calibrations were usually less than $0.3 \%$. All pipettes and burettes were calibrated using water and $3.0 \mathrm{M} \mathrm{NaClO}$.

Table" 3. ExperimentalFdata $(B, A)_{b, h}$ and $B(b, A)_{h}$ for $-\log h=6.782$. The points used in the Letagrop refinement are indicated by $\Delta B=\left(B_{\text {calc }}-B_{\text {exp }}\right)$ and their sign. In calculating $B_{\text {calc }}$ we used Set 3 of Table 4 and the $\delta B$ values listed in the head of each titration.

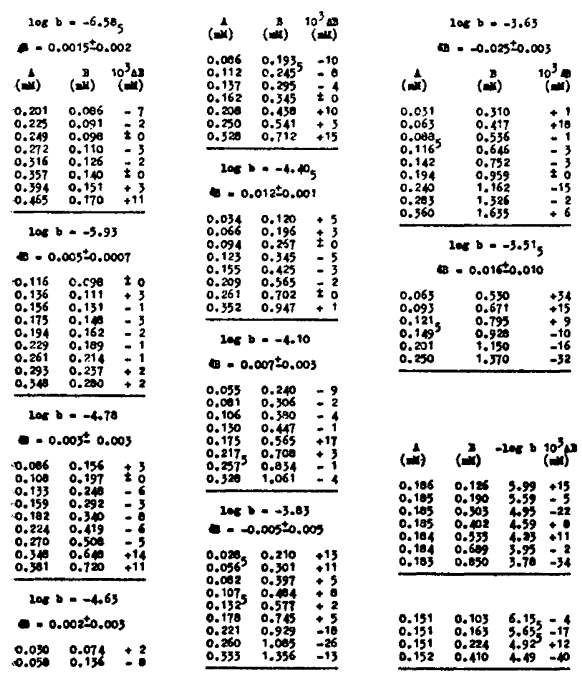

Acta Chem. Scand. 25 (1971) No. 10 
Table 4. Results of Letagrop treatment, data $B(A)_{b, h}$.

\begin{tabular}{|c|c|c|c|c|c|c|c|c|}
\hline No. & $\begin{array}{c}10^{-6} \times \\
F_{11} F_{01}^{-1}\end{array}$ & $\begin{array}{l}10^{-11} \times \\
F_{21} F_{01}{ }^{-1}\end{array}$ & $\begin{array}{l}10^{-10} \times \\
F_{41} F_{01}{ }^{-1}\end{array}$ & $\begin{array}{l}10^{-35} \times \\
F_{82} F_{01}{ }^{-2}\end{array}$ & $\begin{array}{c}10^{-00} \times \\
F_{16,4} F_{01}{ }^{-4}\end{array}$ & $\begin{array}{l}10^{-144} \times \\
F_{26,8} F_{01}{ }^{-6}\end{array}$ & $10^{2} \sigma(B)$ & $10^{\circ} \mathrm{U}$ \\
\hline 1 & $2.4 \pm 0.2$ & $1.5 \pm 0.2$ & - & $2.0 \pm 0.2$ & $1.8 \pm 0.4$ & - & 2.1 & 30 \\
\hline 2 & $2.44 \pm 0.10$ & $1.2 \pm 0.1$ & - & $1.96 \pm 0.11$ & $0.66 \pm 0.15$ & $1.0 \pm 0.2$ & 1.6 & 19 \\
\hline $3^{a}$ & $2.31 \pm 0.08$ & $1.35 \pm 0.1$ & - & $1.70 \pm 0.08$ & $0.64 \pm 0.09$ & $1.2 \pm 0.2$ & 1.0 & 7.6 \\
\hline 4 & $2.0 \pm 0.2$ & $3.9 \pm 0.4$ & $7.6 \pm 0.8$ & - & - & - & 3.0 & 64 \\
\hline $5^{a}$ & $1.8 \pm 0.2$ & $3.5 \pm 0.4$ & $8.3 \pm 0.7$ & - & - & - & 1.9 & 24 \\
\hline
\end{tabular}

${ }^{a} \delta B$ varied.

\section{TREATMENT OF DATA}

The two sets of primary data, $(B, A)_{b, h}$ and $(B, b)_{A, h}$, are shown in Table 3 and are represented graphically in Fig. 1 . The data $(B, A)_{b, h}$ were first analysed by graphical methods and then by using a computer and the general minimizing computer program, Letagropvrid. ${ }^{13}$ It was assumed that the equilibria in the zinc(II)-albumin system can be described by the general reaction

$$
p \mathrm{Zn}^{2+}+q \mathrm{H}^{+}+r \mathrm{~A}^{y-} \rightleftharpoons \mathrm{Zn}_{p} \mathrm{H}_{q} \mathrm{~A}_{r}^{(2 p+q-r y)+}
$$

and the equilibrium constant, $\beta_{p q r}$.

The results obtained were found to be consistent by the formation of the monomers $\mathrm{ZnL}$ and $\mathrm{Zn}_{2} \mathrm{~L}$, and the polymers $\mathrm{Zn}_{6} \mathrm{~L}_{2}, \mathrm{Zn}_{16} \mathrm{~L}_{4}$, and $\mathrm{Zn}_{26} \mathrm{~L}_{6}$. The corresponding constants, $\left(F_{p r} F_{01}\right)$, are shown in Table 4 (Set 3), and their logarithms on p. 3837.

The potentiostatic method

For a constant value for $h$ we obtain from mass balances:

where

$$
\begin{gathered}
A=a+\sum_{q} \sum_{r} r h^{q} a^{r} \beta_{0 q r}+\sum_{p} \sum_{q} \sum_{r} r b^{p} h^{q} a^{r} \beta_{p q r}=\sum_{r} r a^{r} F_{0 r}+\sum_{p} \sum_{r} r b^{p} a^{r} F_{p r} \\
B=b+\sum_{p} \sum_{q} \sum_{r} p b^{p} h^{q} a^{r} \beta_{p q r}=b+\sum_{p} \sum_{r} p b^{p} a^{r} F_{p r}
\end{gathered}
$$

$$
F_{p r}=\sum_{q} h^{q} \beta_{p q r}
$$

From measurements at different levels of $h$ one may, for each level, deduce the most important values of $p$ and $r$ using eqns. 4 and 5. Then, in principle, the variation of the $F_{p r}$ with $h$ (eqn. 6) enables us to deduce the prevailing values of $q$.

For constant values of both $h$ and $b$, eqns. 4 and 5 reduce to the relationships

$$
A=\sum_{r} r a^{r} G_{r}
$$


where

$$
B=b+\sum_{r} a^{r} S_{r}
$$

$$
G_{r}=\sum_{p \geq 0} b^{p} F_{p r} ; S_{r}=\sum_{p \geq 1} p b^{p} F_{p r}
$$

Now, if $r$ is equal to unity, eqns. 4a and 5 a may be written

$$
A=a G_{1} ; B=b+a S_{1}=b+A \cdot \text { constant }
$$

It follows from eqn. 5b that a straight line is obtained if $B$ is plotted against $A$ with $h$ and $b$ constant.

$$
\text { Graphical analysis }
$$

It is shown by Fig. 1 that the data follow straight lines for high $-\log b$ but concave curves for low - $\log b$. This indicates that mononuclear albumin complexes, $r=1$, predominate at high $-\log b$ (eqn. 5b). From the plot, $Z_{B}$ against $\log b$, these mononuclear species were found to be $\mathrm{ZnL}$ and $\mathrm{Zn}_{2} \mathrm{~L}$. By comparison to normalized graphs ${ }^{14}$ we obtained the following values for the logarithm of the constants $F_{11} F_{01}{ }^{-1}$ and $F_{21} F_{01}{ }^{-1}$ :

$$
\log \left(F_{11} F_{01}{ }^{-1}\right)=6.3 ; \log \left(F_{21} F_{01}^{-1}\right)=11.15
$$

In order to analyse the equilibria at low $-\log b$, where polynuclear albumin complexes may exist, we first calculate $\log$ a/A as defined by

$$
\log \mathbf{a} / \mathrm{A}=\log a F_{01} / A=\log \left(\left(a \sum_{q \geq 0} h^{q} \beta_{0 q 1}\right) / A\right)=\log a / a_{0}
$$

The quantity $\log a / a_{0}$ is given by the equation

$$
\log a / a_{0}=-\int_{-\infty}^{\log b}(\delta B / \delta A)_{b, h} \mathrm{~d} \log b \quad \text { at } A, h \text { constant }
$$

This relationship is derived in the same manner as has been previously described for similar equations ${ }^{\mathbf{1 2}, 15}$ ( $c f$. Ref. 16). It is assumed in eqn. 9 that all the acidbase species $H_{q} A$, can be approximated to be of the mononuclear $\mathrm{H}_{q} \mathrm{~A}$ type.

In the next step we calculate the values of $p$ and $r$ for the predominating species $\mathrm{Zn}_{p} \mathrm{~L}$, using the equations

$$
\begin{aligned}
& p=(\Delta \log (B-b) / \Delta \log b)_{h, \mathbf{a}} \\
& r=(\Delta \log (B-b) / \Delta \log \mathbf{a})_{h, b}
\end{aligned}
$$

For high $B$, most of the albumin exists as zinc complexes. The value of $p$ may then be calculated from the equation

$$
p=r(\Delta B / \Delta A)_{b, h}
$$

Eqns. 11-13 presuppose that in each concentration range considered there is only one main complex in the solution.

Fig. 2 shows that the data, $\log (B-b)$ against $\log a$, can be fitted to straight lines. Their slopes, $r$, increase with $b$ and attain values from 1 to 6 . When the values of $p$ are plotted against these $r$ 's in a $(\bar{p} ; \bar{r})$ diagram, a great deal of the 
data follow the line, $p=5 r-4$ (Fig. 3). The complexes formed in the solution must then have the composition, $\mathrm{Zn}_{-4}\left(\mathrm{Zn}_{5} \mathrm{~L}\right)_{n}$ with values of $n$ from 1 to 6 .

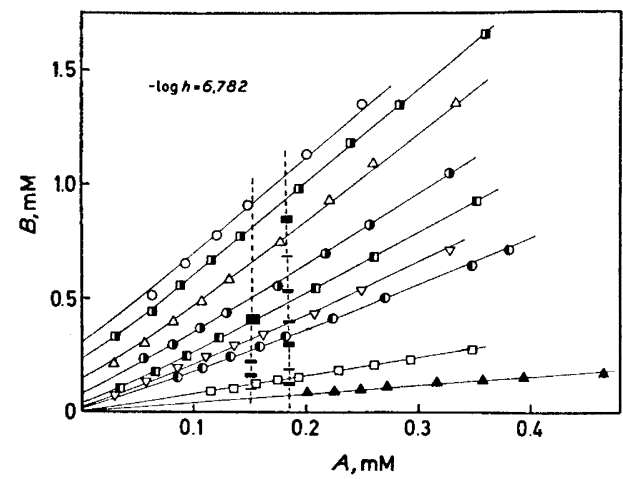

Fig. 1. Zinc(II) complexes of plasma albumin in $0.5 \mathrm{M} \mathrm{NaClO}_{4}$ at $25^{\circ}$ and $-\log h=6.78_{2}$. The symbols are the experimental points and the curves have been calculated assuming the equilibrium constants of Table 4 (Set 3). For data $B(A)_{b, h}$ the values of $-\log b$ are: 0 , $3.515 ;[\square, 3.63 ; \triangle, 3.83 ; O, 4.10 ; \square], 4.405$; $\nabla, 4.63 ; 0,4.78 ; \square, 5.93 ; \Delta, 6.585$. For data $B(b, A)_{h}$ symbols, - , of heights equal to $B_{\text {calc }}-B_{\text {exp }}$.

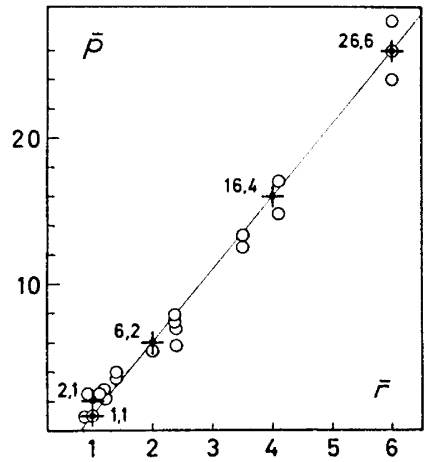

Fig. 3. The average numbers of zinc ions $(\bar{p})$ and albumin molecules $(\bar{r})$ bound in complexes $\mathrm{Zn}_{p} \mathrm{~L}_{r}$. Points corresponding to predominating species are indicated by their pairs of $(p, r)$. Note that all points except $(2,1)$ fall on the straight line, $p=5 r-4$.

Acta Chem. Scand. 25 (1971) No. 10

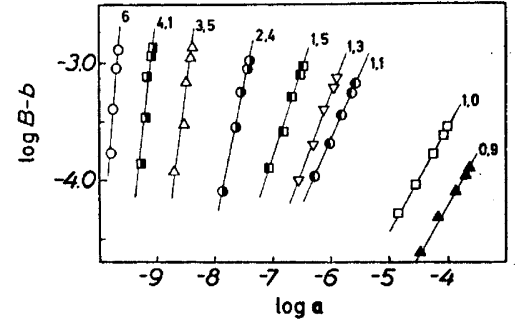

Fig. 2. The determination of $r$, the prevailing number of albumin molecules bound in the complex $\mathrm{Zn}_{p} \mathrm{~L}_{r}$. The data, $\log (B-b)$ against $\log a$, have been fitted to straight lines, and the slopes are indicated ( $c f$. eqn. 12). For symbols, see legend to Fig. 1.

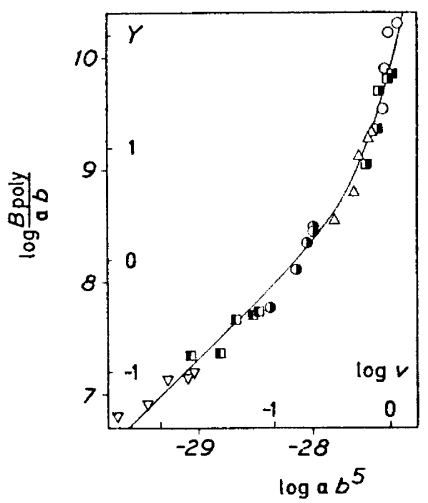

Fig. 4. Data $\log B_{\text {poly }} / \mathrm{a} b$ against log $a b^{5}$ of eqn. 14 compared with the model function, $Y=\log \left(6 v+16 v^{3}+26 v^{5}\right)$. For symbols, see legend to Fig. 1. 
When the data, $\log B_{\text {poly }} / \mathbf{a} b$ against $\log \mathbf{a} b^{5}$, were compared to curves calculated from normalized model functions, $Y(\log v)$, it was found that these data could be explained by only two parameters (Fig. 4). The equation

$$
\begin{aligned}
& \log B_{\text {poly }}-\log a b=\log \left(B-b-a b F_{11} F_{01}{ }^{-1}-2 a b^{2} F_{21} F_{01}{ }^{-1}\right)-\log a b \\
& =\log \left(6 a b^{5} K_{0}+16\left(a b^{5}\right)^{3} K_{0} K+26\left(a b^{5}\right)^{5} K_{0} K^{2}\right)
\end{aligned}
$$

was normalized to

$$
Y=\log \left(6 v+16 v^{3}+26 v^{5}\right)
$$

In eqn. 14 a series of complexes, $\mathrm{Zn}_{6+10 s} \mathrm{~L}_{2+2 s}$ with $8=0,1$, and 2 , is assumed. The constant, $K$, for the addition of a new dimer unit, $\mathrm{Zn}_{10} \mathrm{~L}_{2}$, is assumed to be independent of $s$ for $s \geq 0$. Hence, the constants corresponding to $\mathrm{Zn}_{8} \mathrm{~L}_{2}$, $\mathrm{Zn}_{16} \mathrm{~L}_{4}$, and $\mathrm{Zn}_{26} \mathrm{~L}_{6}$ of the series may be written $K_{0}, K_{0} K$, and $K_{0} K^{2}$. This also defines the constant $K_{0}$. The variables $(Y, \log v)$ of eqn. 15 are logarithms of products containing $\left(B_{\text {poly }} / \mathbf{a} b, \mathbf{a} b^{5}\right)$ and the constants $\left(K^{1 / 2} K_{0}^{-1}, K^{1 / 2}\right)$. In the position of the best fit these constants are obtained from the differences in readings on the calculated and experimental scales (Fig. 4). For $s=0,1$, and 2 this gave

$$
\log F_{6+10 s, 2+2 s} F_{01}{ }^{-(2+2 s)}=\log K_{0}+s \log K=35.5+s 54.6
$$

\section{REFINEMENT OF CONSTANTS}

The data were treated with the second version of the program Letagrop. ${ }^{13}$ We searched for these values of the constants, $F_{p r} / F_{01}$, that minimize $U$, the error square sum:

$$
U=\sum\left(B_{\text {calc }}-B_{\text {exp }}\right)^{2}
$$

The special block, "Ubbe", of this program was rewritten for the present problem. From the data $(\log b, A)$ the computer first calculated the quantity, $a$, using the preliminary constants $F_{p} F_{01} \rightarrow$. The first constants were those obtained graphically. The machine then computed the quantity $a^{r} b^{p} F_{p} F_{01} \rightarrow$ corresponding to each species $\mathrm{Zn}_{p} \mathrm{~L}$, and finally $B_{\text {calc }}$. During this treatment we attempted to explain the data by sets of other species having compositions rather close to the graphical ones. We also assumed that in each series of experiments there is a constant error, $\delta B$, which may be due to, for instance, analytical errors in $B$ and $A$ or to errors in the constants, $E_{0 \mathrm{G}}$ and $E_{0 \mathrm{Zn}}$ (Ref. 13).

It is shown by Table 4 that we have to assume both the polymers $\mathrm{Zn}_{6} \mathrm{~L}_{2}$, $\mathrm{Zn}_{16} \mathrm{~L}_{4}$, and $\mathrm{Zn}_{26} \mathrm{~L}_{6}$ and the monomers $\mathrm{ZnL}$ and $\mathrm{Zn}_{2} \mathrm{~L}$ in order to explain the data (Set 2). When these polymers are replaced by the monomer $\mathrm{Zn}_{4} \mathrm{~L}$ there are marked increases both in $\sigma(B)$ and in the error square sum, $U$, whether the systematic errors are considered or not (Sets 4 and 5). For the set including polymers (Set 3 ) these systematic errors were about $1 \%$ compared to the $10 \%$ for Set 5 . Also, when we attempted to introduce the monomers $\mathrm{Zn}_{3} \mathrm{~L}$ and $\mathrm{Zn}_{5} \mathrm{~L}$ into Set 4 we neither obtained any significant reduction in $\sigma(B)$ nor in $U$. Their constants came out with large errors. This was also the case when the species $\mathrm{Zn}_{3} \mathrm{~L}, \mathrm{Zn}_{4} \mathrm{~L}$, and $\mathrm{Zn}_{5} \mathrm{~L}$ were introduced into Set 2.

When a number of dimeric species $(r=2)$ having values of $p$ equal to $1,2,5$, and 7 were successively tested in Set 2 and the constants varied together, there was not an improved agreement with the experimental data. Some 
of these dimeric species were rejected by Operation Miko of the program.13 Others came out with constants having very large errors. Thus, the present data do not provide evidence concerning the possible presence of dimers in the albumin stock solutions, even though commercial albumin preparations are known to contain a certain amount of dimers. ${ }^{17}$ If these do exist, we may conclude that their concentrations are not greater than $5 \%$ (cf.p. 3829). It should also be born in mind that our albumin solutions were not subjected to pH's lower than 5.5 ( $c f$. Ref. 18), i.e. they were prepared under experimental conditions that might reduce side reactions of sulfhydryl groups.

When recalculated to $\log \left(F_{p,} F_{01} \vec{r}\right)$ and giving $3 \sigma$ limits, Set 3 becomes

$$
\begin{aligned}
& \log F_{11} F_{01}{ }^{-1}=6.36 \pm 0.05, \\
& \log F_{62} F_{01}{ }^{-2}=35.23 \pm 0.07, \\
& \log F_{26,6} F_{01}^{-6}=144.1(<144.3)
\end{aligned}
$$$$
\log F_{21} F_{01}{ }^{-1}=11.1 \pm 0.1 \text {, }
$$

$$
\log F_{16,4} F_{01}^{-4}=89.8 \pm 0.2 \text {, }
$$

As an important test of the accuracy of our calculations let us consider Fig. 1 and Table 3. They show that the data of the present accuracy may be satisfactorily described by Set 3 of Table 4.

Fig. 5 shows the distribution of zinc ions between the different species as a function of $-\log b$ at $\mathrm{pH}$ 6.78. In this system the distribution is also a function of the albumin concentration. The values of $A$ in Fig. 5 are the border values for the range studied.

Fig. 5. Distribution of zinc(II) ions between different complexes at $\mathrm{pH} 6.78 \mathrm{ex}$ pressed as moles per 100 moles. The assumed constants were Set 3 in Table 4. For a certain $-\log b$, the moles per 100 moles of zinc ions present as a given species are represented by the segment of the vertical line falling within the corresponding range. The minor species are indicated by their $p, r$ values in the formula $\mathrm{Zn}_{p} \mathrm{~L}$, . Full drawn curves, experimental range; broken curves, extrapolated range.

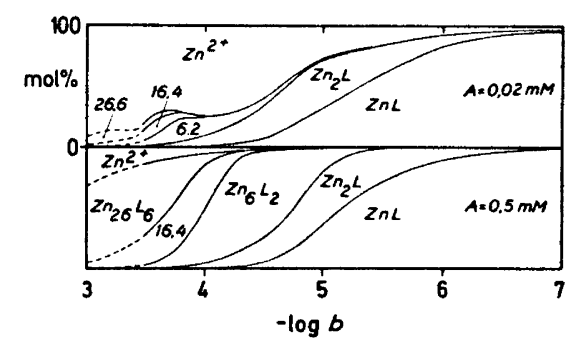

\section{DISCUSSION}

The calculations presented in the previous section have furnished evidence for the formation of the monomeric species $\mathrm{ZnL}$ and $\mathrm{Zn}_{2} \mathrm{~L}$ and for the presence of the polymers $\mathrm{Zn}_{6} \mathrm{~L}_{2}, \mathrm{Zn}_{16} \mathrm{~L}_{4}$, and $\mathrm{Zn}_{26} \mathrm{~L}_{6}$. The existence of $\mathrm{Zn}_{2} \mathrm{~L}$ has been reported previously by Rao and Lal. ${ }^{19}$ Our data agree with the suggestion of these authors that the albumin molecule has two binding sites for zinc ions which form much stronger complexes than other binding sites. However, our data also indicate that there is a definite difference in stability between the first and the second association steps. Thus, at low concentrations of both albumin and zinc ions the species $\mathrm{ZnL}$ predominates (Fig. 5). It appears to be the most important species in the concentration ranges of human blood plasma, $A=0.6 \mathrm{mM}, B=0.05 \mathrm{mM}$ (Figs. 1 and 5 ). (Human and bovine albumins have rather similar compositions and properties ( $c f$. Refs. 18, 20).) 
When the zinc ion concentration becomes about $0.5 \mathrm{mM}$ in the present concentration range of albumin, the albumin molecules tend to condense into polymers of composition $\mathrm{ZnL}\left(\mathrm{Zn}_{5} \mathrm{~L}\right)_{n}$ (Figs. 1 and 5 ). Of these, we have identified $\mathrm{Zn}_{6} \mathrm{~L}_{2}, \mathrm{Zn}_{16} \mathrm{~L}_{4}$, and $\mathrm{Zn}_{26} \mathrm{~L}_{6}$, and we may assume that the process continues further for higher zinc ion concentrations. This is substantiated by the fact that albumin causes precipitates in $0.5 \mathrm{M} \mathrm{NaClO}_{4}$ medium at zinc ion concentrations as low as $8 \mathrm{mM}$ (p. 3832). Thus, polymerization might be of importance in fractionation procedures, where zinc ions are used as precipitants for albumin. ${ }^{2}$

There is a decrease in $\mathrm{pH}$ when zinc ions react with albumin (Table 2). This indicates that the complex formations involve groups that are, if only partly, protonated at $\mathrm{pH}$ 6.8. Among these groups present in albumin we might tentatively assume that the zinc ions are bound to the single thiol and $\alpha$-amino groupings and also to some of the imidazoles. The thiol group of albumin is known to form very stable complexes with mercury(II) ions (for a review, see Ref. 18). Cupric ions, on the other hand, form their most stable complex with a site involving the amino terminal aspartyl residue.21 The imidazole groups of albumin have repeatedly been assumed to be important ligands for zinc ions., ${ }^{82}$ Also, it has recently been shown that in the crystalline state, sperm whale myoglobin binds a single zinc ion at an imidazole group. ${ }^{23}$

As a first approximation we may assume that only one proton is set free for each zinc ion bound. The magnitudes of the zinc association constants for the monomers may then be estimated from the relationships

$$
K_{11}=F_{11} F_{01}{ }^{-1} h K_{\mathrm{i}}^{-1} ; K_{21}=F_{21} F_{11}{ }^{-1} h K_{\mathrm{i}}^{-1}
$$

where $K_{\mathrm{i}}$ is the intrinsic dissociation constant for the acid-base group involved. The $F$-terms are assumed to differ only in regard to the association of a zinc ion. The values of the $K_{\mathrm{i}}$-constants can be estimated to be $K_{\mathrm{i}}(\mathrm{SH}),=10^{-10.0}$ Ref. 24), and $K_{\mathrm{i}}\left(\alpha-\mathrm{NH}_{3}\right),=10^{-7.9}, K_{\mathrm{i}}(\mathrm{Im}),=10^{-6.9}$ (Refs. 25, 26). Thus, if imidazole groups are assumed, both $K_{11}$ and $K_{21}$ become about three powers of ten greater than the constant reported for the $1: 1$ zinc complex of imidazole (102.6; Ref. 27). The thiol group, on the other hand, gives a $K_{11}$-value, $10^{9.6}$, which is not very far from the $K_{1}$-constants reported for $\mathrm{Zn}^{2+}$-cystein $\left(10^{9.9}\right.$; (Ref. 28) and $\mathrm{Zn}^{2+}$-mercaptoacetic acid (108.0; Ref. 29). Likewise, the introduction of $K_{1}\left(\alpha-\mathrm{NH}_{3}\right)$ into eqn. $17 \mathrm{~b}$ gives a $K_{21}$-value of $10^{5.8}$. This is the same order of magnitude as the values of $K_{1}$ reported for zinc(II) chelates of amino acids (105.5; Ref. 24). Hence, the second zinc association step might involve a bidentate complex, for example formed via the $\alpha$-amino and $\beta$-carboxylate groups of the albumin aspartyl residue (cf. Ref. 19).

If we then extend this procedure to the formation of polymers, we arrive at a conclusion that they form through zinc ions. For example, if the zinc ion binding was independent of the formation of $\mathrm{Zn}_{6} \mathrm{~L}_{2}$, the association constant for the last two zinc ions becomes

$$
K_{\mathrm{ZnIm}}=\left(F_{62} F_{21}{ }^{-2} h^{2} K_{\mathrm{i}(\mathrm{Im})}{ }^{-2}\right)^{1 / 2}=10^{6.6}
$$

This is almost four orders of magnitude greater than the constant reported for zinc-imidazole, ${ }^{27}$ and hence quite improbable. As currently used in the analysis of titration data for proteins we have assumed that the interactions 
of the actual imidazole groups with $\mathrm{H}^{+}$or $\mathrm{Zn}^{2+}$ are identical and independent of each other. One obvious approach to reduce the value of the constant $K_{\mathrm{ZnIm}}$ is to assume that the single thiol groups of both molecules are equally strongly bound to the same zinc ion. Then, we obtain $10^{4.3}$ for $K_{\mathrm{znrm}}$. A further reduction is obtained if a second zinc ion bridge is assumed to be formed by coordination through an imidazole group from each molecule. Provided that $K_{\mathrm{ZnIm}}$ is approximately equal to $K_{\mathrm{Zn}(\mathrm{Im})_{2}}$ the value then becomes $10^{3.4}$.

Similarly, if the formation of $\mathrm{Zn}_{16} \mathrm{~L}_{4}$ from $\mathrm{Zn}^{2+}$ and two $\mathrm{Zn}_{6} \mathrm{~L}_{2}$ would be independent of the zinc ions then

$$
K_{\mathrm{ZnIm}^{\prime}}{ }^{\prime}=\left(F_{16,4} F_{6,2}{ }^{-2} h^{4} K_{\mathrm{i}(\mathrm{Im})}{ }^{-4}\right)^{1 / 4}=10^{5.0}
$$

whereas the mediation of this association process by two zinc ions gives $K_{\text {ZnIm }}{ }^{\prime}=10^{3.4}$. Each zinc ion is assumed to be bound through two imidazoles coming from different dimers. Using the same assumptions, we may also describe the formation of the zinc-imidazole complexes in $Z_{n_{66}} \mathrm{~L}_{6}$ with almost the same constant, $K_{\mathrm{ZnIm}}{ }^{\prime}=10^{3.3}$, provided that a dimer and a tetramer are bound together via two zinc ions. In this hexamer, four of the sixteen available imidazole groups will bind zinc ions. The six albumin molecules will be linked together by ten zinc ions.

In conclusion, it may be remarked that the values of our $F$ constants (Set 3 in Table 4) indicate that the zinc ions induce the formation of albumin polymers. This is supported by the fact that albumin specifically precipitates at a relatively low zinc ion concentration (cf. p. 3832 and Ref. 2 ). It is also widely known that mercury ions form albumin dimers by complex formation via the single thiol group of each molecule. ${ }^{18}$ However, it is only when two zinc ions are assumed to be involved in each of the association steps, $\mathrm{ZnL} \rightarrow \mathrm{Zn}_{6} \mathrm{~L}_{2} \rightarrow \mathrm{Zn}_{16} \mathrm{~L}_{4} \rightarrow \mathrm{Zn}_{26} \mathrm{~L}_{6}$, that we obtain formation constants for zinc-imidazole that are of the same orders of magnitude as the $K_{1}$ constant for the corresponding low-molecular-weight complex. ${ }^{27}$

Acknowledgements. The author is greatly indebted to Dr. Georg Biedermann for valuable discussions, to Dr. Lars Rymo for carrying out the polyacrylamide electrophoresis, and to Mr. Roar Ligaarden for technical assistance.

This work was supported by grants from the Swedish Medical Research Council (Project No. B70-13X-2060) and in part by a grant from the Söderberg's Fund.

\section{REFERENCES}

1. Vesell, E. S. and Bearn, A. G. Proc. Soc. Exptl. Biol. Med. 94 (1957) 96.

2. Cohn, E. J., Gurd, F. R. N., Surgenor, D. M., Barnes, B. A., Brown, R. K., Derouaux, G., Gillespie, J. M., Kahnt, F. W., Lever, W. F., Liu, C. H., Mittelman, D., Mouton, R. F., Schmid, K. and Uroma, E. J. Am. Chem. Soc. 72 (1950) 465.

3. Squire, P. G., Moser, P. and O'Konski, C. T. Biochemistry 7 (1968) 4261.

4. Biedermann, G and Ciavatta, L. Arkiv Kemi 22 (1964) 253.

5. Biedermann, G., Newman, L. and Ohtaki, H. Symposium on Trace Characterization, Oct. 3-\%, National Bureau of Standards, Gaithersburg, Maryland 1966, p. 1.

6. Benson, E. S., Hallaway, B. E. and Lumry, R. W. J. Biol. Chem. 239 (1964) 122.

7. Biedermann, G. Personal communication.

8. Gurd, F. R. N. and Goodman, D. S. J. Am. Chem. Soc. 74 (1952) 670.

9. Österberg, R. European J. Biochem. 13 (1970) 493.

10. Biedermann, G. Svensk Kem. Tidskr. 76 (1964) 362.

Acta Chem. Scand. 25 (1971) No. 10 
11. Leden, I. Doctoral dissertation, University of Lund 1943.

12. Osterberg, R. Acta Chem. Scand. 19 (1965) 1445.

13. Ingri, N. and Sillén, L. G. Arkiv Kemi 23 (1965) 97.

14. Sillén, L. G. Acta Chem. Scand. 10 (1956) 186.

15. Osterberg, R. Doctoral dissertation, University of Göteborg 1966.

16. Sillén, L. G. Acta Chem. Scand. 15 (1961) 1981.

17. Petersen, H. A. and Foster, J. F. J. Biol. Chem. 240 (1965) 2503.

18. Foster, J. F. In Putnam, F. W., Ed., The Plasma Proteins, Academic, New York 1960 , Yol. I, p. 179.

19. Rao, M. S. N. and Lal, H. J. Am. Chem. Soc. 80 (1958) 3222, 3226.

20. Perkins, D. J. Biochem. J. 80 (1961) 668.

21. Peters, T. and Blumenstock, F. A. J. Biol. Chem. 242 (1967) 1574.

22. Gurd, F. R. N. and Wilcox, P. E. Advan. Protein Chem. 11 (1956) 311.

23. Banaszak, L. J., Watson, H. C. and Kendrew, J. C. J. Mol. Biol. 12 (1965) 130.

24. Martell, A. E. and Sillén, L. G. Stability Constants, Special Publication No. 17, The Chemical Society, London 1964.

25. Tanford, C., Swanson, S. A. and Shore, W. S. J. Am. Chem. Soc. 77 (1955) 6414.

26. Österberg, R. J. Phys. Chem. 73 (1969) 2230.

27. Nozaki, Y., Gurd, F. R. N., Chen, R. F. and Edsall, J. T. J. Am. Chem. Soc. 79 (1957) 2123 .

28. $\mathrm{Li}$, N. C. and Manning, R. A. J. Am. Chem. Soc. 77 (1955) 5225.

29. Loussing, D. L. J. Am. Chem. Soc. 80 (1958) 4180.

30. Tanford, C. J. Am. Chem. Soc. 74 (1952) 211.

31. Saroff, H. A. and Mark, H. J. J. Am. Chem. Soc. 75 (1953) 1420.

32. Kacena, V. Chem. Listy 48 (1954) 7.

33. Waldmann-Meyer, H. J. Biol. Chem. 235 (1960) 3337.

Received February 24, 1971. 